\title{
O DE RE RUSTICA II DE VARRÃO REATINO E A COMÉDIA GRECO-ROMANA: ANALOGIAS ${ }^{1}$
}

\author{
Matheus Trevizam* \\ Resumo: O segundo livro do De re rustica de Varrão \\ de Reate (séc. I a.C.), como os demais da mesma obra, \\ também apresenta, apesar de pertencer ao gênero \\ dialógico da literatura antiga, afinidades com a Comédia \\ greco-latina. Propomo-nos, aqui, a elucidar-lhe as \\ características que nos permitem essa última afirmação. \\ Palavras-chave: Literatura clássica; Varrão; gênero \\ dialógico; Comédia.
}

\section{Introdução}

Confrontados com uma obra como o De re rustica varroniano, constatamos com outros leitores a presença, na tessitura desse texto técnico antigo, de elementos e funções alheios ao intento de informar o público nos âmbitos práticos da agricultura e da arboricultura (livro I), da pecuária de grande e

\footnotetext{
${ }^{1}$ Este artigo se insere como parte do projeto de pesquisa "Tradução anotada e estudo dirigido do segundo livro do De re rustica de Varrão de Reate", desenvolvido na FALE-UFMG pelo "Programa de auxílio para a pesquisa dos doutores recém-contratados", com o apoio da PRPq.

* Universidade Federal de Minas Gerais.
} 
pequeno porte (livro II) e da uillatica pastio (livro III). ${ }^{2}$ Decerto desejoso de afinar-se com a moda literária de sua época, que teve num Cícero o amiudado escritor de vários diálogos de tema filosófico ou retórico, ${ }^{3}$ Varrão, ainda, pôs a serviço dos próprios intentos divulgadores das artes agrárias certos recursos expressivos passíveis de aproximar-lhe, neste caso, o fazer artístico do universo dramático.

Alguns esclarecimentos de caráter genérico se fazem necessários aqui: de fato, inegavelmente, a tipologia compositiva antiga a prevalecer em todo o De re rustica corresponde à do gênero dialógico. Isso significa, como nos esclarecem os filólogos, que se trata de dar a voz a interlocutores textualmente trabalhados a fim de que, imbuídos de saberes e opiniões, transmitam-nos por turnos interacionais a seus pares no próprio contexto ficcional ou, em última instância, ao público receptor do texto. ${ }^{4}$ Obviamente, não se trata de um direcionamento excludente do ato comunicativo, pois, considerando o necessário "voyeurismo" da operação de leitura de obras dialógicas (ou epistolográficas ${ }^{5}$ e didáticas antigas) ${ }^{6}$ quaisquer, vê-se sempre o público ao mesmo tempo confrontado com as informações sobre que "conversam" as personagens e com a "escuta" de uma performance comunicativa em que não toma parte de maneira direta.

Por outro lado, dentre todas as formas de uso artístico da palavra disponíveis na Antiguidade, talvez seja o diálogo a que

\footnotetext{
${ }^{2}$ Villatica pastio é, na concepção varroniana da Economia agrária, a criação de pequenos animais (peixes, lebres, aves, abelhas...) nas imediações das casassede dos antigos fundi ("propriedades") romanos, com fins de deleite ou lucro dos senhores.

3 TRAGLIA. Varrone e la prosa letteraria del suo tempo, p. 497-498.

${ }^{4}$ GAILLARD; MARTIN. Les genres littéraires à Rome, p. 221-222.

${ }^{5}$ GAILLARD; MARTIN. Les genres littéraires à Rome, p. 454-456.

${ }^{6}$ GAILLARD; MARTIN. Les genres littéraires à Rome, p. 198-200.
} 
mais se aproxima do teatro (ou vice-versa). Um capítulo de autoria de Clay propõe, inclusive, remontar as origens do gênero dialógico na literatura grega ao âmbito de certa produção dramática (os Mimos áticos). ${ }^{7}$ De início, segundo esse crítico anglófono, importa entender que os pioneiros diálogos socráticos, cujos mais antigos espécimes extensivamente conservados para os modernos correspondem à produção platônica, não nasceram prontos das mãos do filósofo ateniense: tem-se, mesmo, notícia de variada escrita extra de textos a tomarem Sócrates como objeto imitativo em interação dialogada com outras personagens. Tal é o caso, por exemplo, das obras (quase sempre perdidas) de Ésquines, de Antístenes, e do próprio Xenofonte de Atenas... ${ }^{8}$

Seja como for, uma vez oferecida a definição geral dos "diálogos platônicos" (os textos dialogados compostos por Platão e tendo como protagonista a figura histórica de Sócrates) como "imitações de personagens humanas em prosa que não são narrativas, mas articuladas por pergunta e resposta", 9 o autor parte em busca de analogias entre essa produção e formas teatrais em que também assistimos à direta recorrência às palavras e gestos dos interlocutores como base construtiva da performance. São elas os Mimos siracusanos, a Comédia siciliana e os Mimos áticos. No primeiro caso, como se trata, segundo documentam as notícias supérstites sobre Sófron, de imitações a envolverem tipos cômicos (nunca personagens históricas contemporâneas!), em que a construção dialogada parece rara, Clay prefere desconsiderar as "pistas" antigas que apontariam para um suposto enraizamento dialógico em tais Mimos; ${ }^{10}$ no segundo, em que a produção cômica é representada pelo siciliano Epicarmo, há, por sua vez, a

\footnotetext{
${ }^{7}$ CLAY. The origins of the socratic dialogue, p. 37-41.

${ }^{8}$ CLAY. The origins of the socratic dialogue, p. 26-33.

${ }^{9}$ CLAY. The origins of the socratic dialogue, p. 34-35.

${ }^{10}$ CLAY. The origins of the socratic dialogue, p. 35-36.
} 
recorrência ao dialeto dórico e aos versos para a escrita de peças "miméticas e dramáticas em seu estilo", mas, eventualmente, míticas. ${ }^{11}$ Desse modo, também estaríamos, para Clay, diante de um ponto de partida falho ao tomarmos Epicarmo para suposto inspirador genérico do fazer dos escritores dialógicos antigos...

Quando se vê diante dos traços da Comédia Velha ateniense, porém, segundo arquetipicamente representada por Aristófanes, o mesmo crítico inclina-se a ter encontrado respostas mais plausíveis para o tópico da origem genérica em pauta:

O único tipo de poesia conhecido por mim que nos oferece um modelo claro para os Sôkratikoi logoi e a mímese das conversas de uma personagem histórica contemporânea como Sócrates é a comédia ática. (...) Um dos traços surpreendentes de nossa primeira apresentação dos Sôkratikoi logoi no palco cômico (Nub. 482-88) é que tal questionamento envolve não só pergunta e resposta, mas o julgamento de uma personagem. Ao fazer perguntas a Estrepsíades, Sócrates está mais interessado em vir a entender-lhe o caráter do que em encontrar respostas para questões que, genuinamente, o deixam perplexo. ${ }^{12}$

Na sequência do capítulo, Clay investiga ainda, o que nos interessa um pouco menos para os propósitos deste artigo, os traços da Tragédia e da História que se poderiam ter importado para o universo criativo dos diálogos. Seriam eles, de uma forma que não julgamos, todavia, posta tão decisivamente do ponto de vista da origem genérica por este estudioso, a tematização de um "mito" (pois Sócrates, para os coevos aos escritores de diálogos socráticos, tornara-se, via de regra, uma figura destacada do passado [recente], cujas vicissitudes eram bem conhecidas) ${ }^{13}$ e a

\footnotetext{
${ }^{11}$ CLAY. The origins of the socratic dialogue, p. 36-37.

${ }^{12}$ CLAY. The origins of the socratic dialogue, p. 37-38. (tradução nossa do inglês)

${ }^{13}$ CLAY. The origins of the socratic dialogue, p. 45.
} 
inserção de um pano de fundo factual para o desenvolvimento da ação. A respeito desse último ponto, citando a abertura do Cármides de Platão como exemplo comprobatório (pois, nela, fazem-se precisas menções não apenas à batalha de Potideia, mas, ainda, ao envolvimento de Sócrates neste episódio da história helênica), Clay entende que se trataria, especificamente, de um aporte platônico ao universo expressivo do gênero dialógico. ${ }^{14}$

Em que pese ao fato de tais proposições serem hipotéticas (como é compreensível diante do trabalho com letras tão antigas!) e de, na verdade, o subtipo dialógico encontrado no caso específico dos sermones agrários varronianos corresponder à variedade aristotélica, ${ }^{15}$ acreditamos em que o dito até o presente momento serve-nos de acesso para a específica leitura do livro II do De re rustica como produto literário também afinado com a Comédia antiga. Afinal, independentemente do tipo genérico interno ao dialogismo que se possa ter seguido e do caráter apenas especulativo das ideias de Clay, em todo caso partilhamos com ele a mínima visão da interpenetrabilidade possível entre um e outro domínio artístico, dado o modo direto - e, tantas vezes, dialogadode imitação das personagens e as chances de importar com irreverência figuras verídicas para a cena.

\section{Traços de teatralidade no livro II do De re rustica de Varrão}

Chega ao leitor dos diálogos agrários varronianos, talvez como primeira e mais forte impressão, a capacidade do autor de evocar toda uma ambientação de enquadramento das interações entre as personagens. ${ }^{16}$ Esse recurso, que não se deve confundir

\footnotetext{
${ }^{14}$ CLAY. The origins of the socratic dialogue, p. 43.

${ }^{15}$ RUCH. Le préambule dans les ouvres philosophiques de Cicéron. Essai sur la genèse et l'art du dialogue, p. 40-42.

${ }^{16}$ TREVIZAM. Linguagem e interpretação na literatura agrária latina, p. 92-93.
} 
com o mero esboço de um cenário ou espaço físico de ocorrência dos diálogos, vale-se, ainda, dos assuntos exclusivamente tratados ao longo de cada livro, da antroponímia latina e de circunstâncias temporais em algum nexo com os tipos de temas abordados. Devemos observar, no cotejo com a produção cômica antiga, que algo similar ocorria, por exemplo, na chamada palliata romana, que teve em Terêncio e, sobretudo, em Plauto, seus mais importantes expoentes. Ora, embora avisados da generalidade básica dos enredos a adentrar as peças desses comediógrafos, muitas vezes identificados com a resolução feliz (e ardilosa) de um impasse amoroso entre um jovem e uma moça com quem, em princípio, a felicidade parecia impossível, ${ }^{17}$ não se devem omitir as chances de categorização das peças por suas características intrínsecas. Assim, por um lado seria possível, na vasta produção plautina, destacar as peças em que o tema da prostituição dá o tom (Asinaria, Bacchides, Cistellaria, Truculentus...) e, por outro, aquelas em que se apaga, para desenrolarem-se os conflitos em outros planos da experiência (Amphitruo, Aulularia, Menaechmi...). Numa peça como a Aulularia, fortemente centrada no impasse de uma adolescente violentada por um jovem vizinho bêbado - com a consequente gravidez indesejada da moça e as tentativas de muitos de minimizarem os decorrentes prejuízos a ela e à sua família -, a "atmosfera" sabe ao mundo doméstico das famílias romanas empobrecidas, amiúde às voltas com problemas práticos de sobrevivência e atacadas em sua estabilidade pelas vicissitudes do destino. Portanto, assiste-se aqui não a um cortejo de devassos, proxenetas e "patifes" às portas de um lupanar mal-afamado, mas, sim, à animada movimentação de criados, vizinhos e parentes de algum modo envolvidos na trama familiar evocada, com as preocupações, afazeres e traços caracterizadores (nomes, gestual, hábitos mentais...) tipicamente associáveis a indivíduos de suas respectivas condições sociais. $\mathrm{O}$ cenário de desenvolvimento da

${ }^{17}$ GRIMAL. O teatro antigo, p. 67-68. 
trama, tal como se mostrava ao público no palco de representação, correspondia, na Aulularia, às fachadas das casas de Megadoro e Euclião, respectivamente, vizinho e pai de Fedra, a moça lesada pelo abuso do impetuoso Licônides. ${ }^{18}$

Quando se tomam para ponto de referência peças como Cistellaria e Bacchides, porém (sendo essa última passada, além de às portas do templo de Apolo e da casa de Nicobulo, o velho tolo da história, em frente ao lupanar onde habitam as duas cortesãs chamadas Báquis), a ambientação e o tom da intriga se modificam por completo:

O mundo das cortesãs que esse teatro nos oferece conforma-se à idéia, pouco favorável, que os contemporâneos de Menandro tinham delas. Diziamse ávidas, incapazes de amar e totalmente desprovidas de senso moral. Não existe "boa cortesã", gostavam de repetir. Plauto ecoa essas idéias recebidas. É assim em Bacchides, em que, como vimos, as duas mulheres, ambas cortesãs, seduzem primeiro os filhos, depois os pais. Todo o início da Cistellaria ("A comédia do cesto") é ocupado por uma conversa entre duas cortesãs, Ginásio e Selênio, em presença da velha Syra, mãe da primeira, e que serve de alcoviteira à sua filha. ${ }^{19}$

Para o livro II da obra, que se ocupa da pecuária e cuja análise propomos aqui, vemo-nos prejudicados em dois dos pontos de ambientação citados acima. Com efeito, entre o final de sua específica praelocutio, que se presta, como também ocorre nos demais livros da obra, a) a propor uma valoração moral positiva das práticas camponesas a abordar-se em seguida, b) a introduzir sutil o discurso sob um viés não técnico e ciosamente

\footnotetext{
${ }^{18}$ PLAUTO. Amphitruo. Asinaria. Aulularia. Bacchides, p. 253.

${ }^{19}$ GRIMAL. La littérature latine, p. 94. (tradução nossa do francês)
} 
vazado sob o cuidado "editorial" de Varrão e c) a nomear o dedicatário de cada livro específico (ou do todo), ${ }^{20}$ e o real início das falas das personagens, interpretamos uma lacuna no texto, não se sabe se movida por perda ou pela própria incompletude do gesto compositivo do autor. Assim, o brusco começo da interlocução entre Cossínio e Varrão, doravante tornado, além de narrador, também personagem do diálogo de sua autoria, e a misteriosa menção a uma eventual partida de Menates correspondem, para nós, a signos de uma falta, pois, à diferença do que se dá nos livros I e III da mesma obra, não nos deixam saber explicitamente onde e quando se reúnem os interlocutores a fim de tratarem em conjunto de muitos tópicos relativos à pecuária.

Baseando-se em possíveis indícios presentes em outras partes do texto, porém, Sylvie Agache observou, sobre as circunstâncias de tempo em que se passa o diálogo de De re rustica II:

O livro II se passa num dia de festa, talvez o dia das Pariliae, festa que corresponde ao dia do aniversário de Roma, como o precisa Varrão em II, 1, 9. O livro articula-se em torno de um entreato, ocasionado pela chegada tardia de Q. Lucieno, que anuncia alto, não sabendo em qual parte da entrevista se está, que há de apressar-se em ir saldar sua dívida para com as Pales. Mas informam-no: não se tratou ainda dos rebanhos de animais de grande porte. ${ }^{21}$

Caso se adote a ideia da crítica francesa, ao menos como hipótese de trabalho, dever-se-ia dizer que a suposta data festiva em jogo não poderia ser mais adequada para situar um diálogo

\footnotetext{
${ }^{20}$ Curiosamente, o livro II e o III do De re rustica são dedicados a Turrânio Níger e a Pínio, mas, no primeiro, o dedicatário do conjunto da obra corresponde a Fundânia, a esposa de Varrão.

${ }^{21}$ AGACHE. Construction dramatique et humour dans le "Traité d'agriculture" de Varron, p. 217-218. (tradução nossa do francês)
} 
de tema pecuário: a cada 21 de abril, como nos informa Robert, ${ }^{22}$ de fato se celebravam em Roma as "Parílias", nas quais ocorriam ritos de caráter eminentemente purificador. Assim, pastores regavam com água as ovelhas e o solo bem limpo, decorando, depois, com guirlandas florais, os redis e a porta de suas casas; acendiam-se fogueiras para a queima do pinho, da oliveira e do loureiro, e os homens saltavam sobre esse fogo para lhe adquirirem a força mágica; enfim, atiravam-se ao fogo as cinzas de um feto de vaca prenhe sacrificada para este objetivo preciso, sangue de cavalo e ramas de favas sem os frutos, bem como se ofereciam ritualmente bolos de cereais e leite aquecido. Esperava-se, com isso, fortalecer, imunizar e tornar férteis os rebanhos.

Sobre o ponto da derivação de comicidade dos nomes rurais das personagens, já bastante explorado pela crítica dedicada a interpretar os diálogos agrários varronianos, ${ }^{23} \mathrm{em}$ que surgem como traço bastante característico, apenas apresentamos em seguida alguns dados necessários à sua compreensão. Em primeiro lugar, nada há de extraordinário ou, sobretudo, fantasioso em existirem romanos dotados de nomes em estreito nexo com o universo camponês. Historicamente, sabemos que a cidade de Roma deve ter-se iniciado com a formação de uma pequena comunidade pastoril e, depois, também agrícola, nas colinas situadas em torno da área antes pantanosa do forum: além dos dados objetivos da arqueologia, comprovam-no em alguma medida as lendas de seu nascimento, que, como sabemos, faziam do pastor Rômulo e de outros moços rústicos os fundadores da Urbe. ${ }^{24}$

Portanto, de uma forma nunca de todo esquecida pelos romanos antigos, a Cidade tivera origens humildes e rurais, o que, em alguma medida, acabou-se por refletir concretamente em sua

22 ROBERT. La vie à la campagne dans l'Antiquité romaine, p. 299-300.

${ }^{23}$ AGACHE. Construction dramatique et humour dans le "Traité d'agriculture" de Varron, p. 203-214.

${ }^{24}$ TREVIZAM. Linguagem e interpretação na literatura agrária latina, p. 15. 
língua e cultura. ${ }^{25} \mathrm{O}$ próprio Varrão, em passagem esclarecedora do De re rustica II, menciona que os latinos tinham "muitos nomes provenientes dos dois tipos de rebanho, o maior e o menor (do menor, Pórcio, Ovínio e Caprílio; mas, do maior, Equício, Táurio e Asínio)", bem como cognomes de mesma origem, "a exemplo dos Ânios Capras, dos Estatílios Tauros e dos Pompônios Vítulos". ${ }^{26}$ Ora, na onomástica romana, um nomen, como Flávio ou Júlio, designava o clã familiar dos cidadãos livres, enquanto correspondia ao praenomen, não mencionado na passagem, o nome próprio dos indivíduos e, ao cognomen, a designação específica de cada família interna aos clãs. ${ }^{27}$ Assim, em Marcus Tullius Cicero, que designa o mais célebre orador de Roma, colhemos as informações de ter ele sido um homem chamado Marco, do clã Túlio e da família dos Cíceros, de resto, também ela dotada de algum vínculo para com o mundo rural, pois se sabe que cicer, em latim, é o nome do grão-de-bico.

O que caracteriza, porém, a destreza compositiva de Varrão a esse respeito é o fato de se terem concentrado, de maneira exclusiva, a cada um dos diálogos rústicos que compõem o todo da obra em pauta, antropônimos em estreito nexo com os "enredos", ou seja, os assuntos sobre que falam as personagens mais capacitadas ao conhecimento dos sucessivos tópicos agrários discutidos. Em De re rustica II, citamos como exemplo dessas personagens Scrofa e Vaccius, em óbvia relação com as palavras latinas para designar a porca (scrofa) e a vaca (uacca).

Especificamente, dadas as associações pouco lisonjeiras do nome de Escrofa, a própria personagem de Gnaeus Tremellius Scrofa se encarrega, em De re rustica II, 4, 1-2, de explicar os motivos da curiosa origem deste seu cognomen:

\footnotetext{
${ }^{25}$ MAROUZEAU. Traité de stylistique latine, p. 144.

${ }^{26}$ VARRÃO. De re rustica II, 1, 10.

${ }^{27}$ SUETÔNIO. Vida de Augusto, VII. (nota 29 dos tradutores).
} 
IV- "Mas quem vem de um porto, de preferência da Itália, e explica sobre as varas de porcos? Seu cognome mostra que Escrofa, antes de mais ninguém, deve falar desse assunto". E a ele Tremélio: "Pareces ignorar, disse, por que me chamo Escrofa. E assim, para que também eles saibam por tua causa, entende que minha gens não tem um nome suíno, nem provim de Eumeu. Meu avô, em primeiro lugar, foi chamado Escrofa. Sendo ele o questor deixado na província da Macedônia sob o pretor Licínio Nerva e comandando o exército até a volta do pretor, os inimigos, por julgarem que era a hora de sua vitória, começaram a fazer incursões contra os acampamentos. $\mathrm{O}$ avô, exortando os soldados a pegarem em armas e atacarem, disse que ele rapidamente os dispersaria, como uma porca os leitõezinhos, e acabou por fazêlo. De fato, naquela batalha, de tal modo dispersou e afugentou os inimigos que, por ela, Nerva foi chamado de imperator, e meu avô recebeu o cognome de Escrofa. E assim, o bisavô e ascendente algum dos Tremélios foi chamado de Escrofa, bem como, em seguida, sou o sétimo ex-pretor em nossa gens. Não me furto, contudo, a dizer o que sei das varas de porcos". ${ }^{28}$

Trocadilhos maliciosos à parte, temos notícia da efetiva e honrosa existência de Escrofa na sociedade romana coeva a Varrão. $\mathrm{Na}$ verdade, essa personagem decerto se insere no contexto dos diálogos rústicos varronianos em lembrança de ter sido, ele mesmo, um importante auctor rerum rusticarum no século I a.C. Segundo observações de René Martin, que dedicou um capítulo inteiro de sua tese doutoral a investigar-lhe as contribuições no domínio da literatura agrária romana, corresponderia ele, malgrado a completa perda de sua obra para nós, modernos, a

\footnotetext{
28 Tradução nossa do latim.
} 
um dos principais expoentes desse campo do saber na Antiguidade latina: com efeito, Varrão, em De re rustica I, 1, 12, Públio Silvino e Plínio, o Velho (Naturalis Historia XVII, 199), demonstram, em alguma medida, respeitoso reconhecimento aos saberes agronômicos desta autoridade técnica, nascida, talvez, por volta de 120 a.C. ${ }^{29}$

Sobre Vácio, oportunamente tomado para porta-voz do tema da criação do gado bovino em De re rustica $\mathrm{II}, 5$, nada sabemos no plano da realidade histórica, mas o nomen Vaccius encontra comprovação na epigrafia latina, não constituindo, pois, mera invenção varroniana. ${ }^{30}$

Deve-se observar que o presente recurso à antroponímia agrária, de resto, funcional para a mínima organização prática da obra (pois, como vimos, Scrofa tratará dos porcos, mas Vácio dos bois e vacas...), encontra, até certo ponto, seus paralelos na produção cômica antiga. Assim, segundo procedimentos conhecidos na arte dramática ocidental pelo menos desde a Comédia Velha grega (séc. V a.C.), Plauto e Terêncio, em Roma, também dotaram suas personagens de antropônimos em estreitos laços com as características e funções dos tipos representados: a título de exemplificação, retomamos, de Plauto (Cistellaria), a supracitada Ginásio (Gymnasium), cujo nome, em suas fontes gregas, na verdade designava um "lugar para exercícios físicos sem roupa", mas, no contexto, evoca com ironia o métier de prostituta da moça, e sua mãe, Syra, claramente uma estrangeira de origem oriental. De Terêncio, por sua vez, encontra-se em $A$ sogra a personagem de um pacato filho de família chamado Pânfilo, a partir de radicais gregos que significam, respectivamente, "todo" e "amigo" (Pânfilo = Amigo de todos, Boa-gente), bem como uma cortesã, por ele amada antes de casar-se, de nome Báquis; no

\footnotetext{
${ }^{29}$ MARTIN. Recherches sur les agronomes latins et leurs conceptions économiques et sociales, p. 242.

${ }^{30}$ SHERK. The eponymous officials of Greek cities, p. 281.
} 
último caso, pois, alude-se, a propósito dessa mulher inserida no mundo de uma profissão do prazer, ao nome do deus Baco, mítico libertador do homem na embriaguez dos sentidos.

Evidentemente, como nos vemos, deparando a galeria de personagens plautinas e de Terêncio, confrontados com tipos, ou seja, figuras cômicas bastante estereotipadas e recorrentes, com pequenas diferenças, em mais de uma peça por motivos de rentabilidade artística, ${ }^{31}$ não seria possível dizer que os interlocutores dos diálogos agrários de Varrão, cujos dois exemplos vistos acima, é bem provável, corresponderam sempre a contemporâneos verídicos do autor na vida romana coeva, sejam exatos paralelos funcionais daqueles. Entretanto, o fato de se encontrarem motivações humorísticas no modo de nomear a tantos e de terem eles papéis bem determinados nas peças dos dramaturgos citados (ou em De re rustica II e nos demais livros da mesma obra!) autoriza-nos, como fizemos, a propor parciais aproximações.

Em se tratando da presença em cena de personagens de todo advindas de tentativas de "retratar" entes sociais verídicos, por sinal, recordamos, no esteio das observações supracitadas de Clay, que a Comédia Velha ateniense, tipicamente representada pela produção aristofânica, com muita frequência tomou para objeto do riso figuras de cidadãos coevos aos dramaturgos. Sabemos, com efeito, além dos ataques a Sócrates como sofista em As nuvens, de peças de pronunciado teor político (e, portanto, de todo comprometidas com a pintura de "retratos" e quadros inseridos na contemporaneidade da vida pública ateniense) que teriam, é provável, angariado a Aristófanes o ódio dos poderosos: paradoxalmente, demasiado crítico da sociedade a acolhê-lo e a permitir-lhe o brilho no cenário dramático do tempo, esse comediógrafo não receou incorrer no desagrado de homens como Cléon, um demagogo. ${ }^{32}$

\footnotetext{
${ }^{31}$ GRIMAL. O teatro antigo, p. 74-76.
}

${ }^{32}$ GRIMAL. O teatro antigo, p. 61. 
Assim, de uma forma que julgamos não de todo fortuita em sua totalidade, poder-se-ia dizer que Varrão de algum modo acaba por "derivar" os traços da ironia contra seus concidadãos $\mathrm{e}$ da transformação de seus nomes num traço compositivo rendoso do ponto de vista humorístico do duplo manancial da Comédia antiga (a Nea grega, de que também foram tributários Plauto e Terêncio em latim, e a Velha, sem diretos representantes na arte dramática romana, mas, como vislumbrou Clay, talvez instigadora da arte dialógica no Ocidente). Deve-se, porém, evitar a proposição de demasiados exclusivismos no ponto da origem cômica de cada um desses traços associáveis a personagens varronianas como Vácio e Escrofa, como se o recurso ao humor dos antropônimos em si tivesse-lhe vindo apenas do plano criativo da Nea ou da Comédia de Plauto e Terêncio e o riso direcionado aos pares, da matriz aristofânica: com efeito, a Comédia Velha, afirmamos, também recorreu amiudada a nomear suas personagens de formas

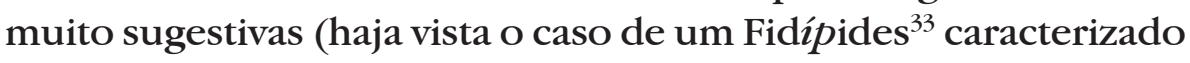
como incorrigível amante do hipismo n'As nuvens mesmas), e a Comédia Nova, embora recorrendo a tipos representativos sem imediato nexo com particulares, não deixou de assimilar características humanas atinentes à sociedade do momento histórico em que se fez. ${ }^{34}$

Por outro lado, talvez não seja inútil mencionar aqui a questão dos jogos de palavras em Varrão: para Laughton, na verdade, este recurso, afim às brincadeiras antroponímicas propriamente ditas e algo matizado (pois que se dá de maneiras atinentes a modos de proceder por vezes distintos...), constitui a própria "alma" do humorismo do autor por sua constante presença e importância em mais de uma obra (como é o caso, além do De re rustica, sobretudo do De lingua Latina). ${ }^{35}$ Então, o

\footnotetext{
33 GRIPP. A língua presa de Fidípides, p. 72.

${ }^{34}$ GRIMAL. O teatro antigo, p. 69-70.

${ }^{35}$ LAUGHTON. Humour in Varro, p. 108.
} 
crítico diferencia ocorrências, como em De re rustica II, 3, 1 (quoniam satis balasti, o Faustule noster, accipe a me... de capellis - "como baliste bastante, ó meu Fáustulo, ouve de mim... sobre as cabras"), ${ }^{36}$ de "menor sutileza" com os jogos verbais de outras em que isso não ocorreria, caso de certo trecho de II, 1, 2 (uos, qui estis Epirotici pecuariae athletae - "vós, que sois atletas epiróticos da pecuária"). ${ }^{37}$ No primeiro exemplo, a troca de "falaste" por "baliste" a propósito do discurso pecuário de Ático seria, na visão de Laughton, um uso apenas motivado pelo contexto associativo imediato (Ático tratara das ovelhas, que balem...), ${ }^{38}$ enquanto a troca de "experts" (periti, ou algo que o valha) por "atletas" (atbletae), com o inevitável sabor irônico e hiperbólico de que se reveste e o inesperado da associação, corresponde a algo mais sutil. ${ }^{39}$ Outro exemplo citado pelo crítico britânico para exemplificar certa afetação construtiva nesses mecanismos, não, contudo, desprovida de efeito, corresponde a uma passagem da praelocutio de De re rustica II, que incide de maneira crítica justamente sobre os patres familiae dos conturbados tempos do autor (quod nunc intra murum fere patres familae correpserunt... et manus mouere maluerunt in theatro ac circo, quam in segetibus ac uinetis - "porque agora os pais de família quase sempre se insinuaram intramuros depois de deixarem a foice e o arado e preferiram mover as mãos no teatro e no circo a fazê-lo nas searas e vinhedos"). ${ }^{40}$ Como no original em inglês, recorre-se ao recurso de citar em latim não destacado por itálico as palavras ou trechos que se deseja ressaltar interpretativamente e Laughton assim procedeu destacando manus ("mãos") e mouere ("mover"),

\footnotetext{
36 Tradução nossa do latim.

${ }^{37}$ Tradução nossa do latim.

${ }^{38}$ LAUGHTON. Humour in Varro, p. 107.

${ }^{39}$ LAUGHTON. Humour in Varro, p. 107.

${ }^{40}$ LAUGHTON. Humour in Varro, p. 108. (tradução nossa do latim)
} 
entendemos que, por força, o crítico deve ter focado alguma tentativa varroniana de jogo verbal e ironia neste ponto específico. Ora, também notamos que tal intérprete não se estende em quaisquer explicações a isso, mas arriscaríamos dizer que, talvez, o efeito apontado por ele corresponderia, aqui, ao fato de serem os dois termos latinos destacados de sonoridade parecida, ambos iniciados pela mesma consoante nasal e paroxítonos. ${ }^{41}$ Assim, acabar-se-ia por depor uma ênfase reiterativa "artificial" (centrada num detalhe miúdo, a necessitar da atenção mais detida do leitor...) precisamente no traço "ruim" de os novos patres preferirem mover as mãos/ agir aplaudindo no teatro... a fazê-lo nos campos em trabalho, à maneira dos laboriosos ancestrais.

Pouco nos importando, nesse contexto, julgar o sucesso de Varrão como proponente de "divertimentos" verbais ou mesmo de Laughton como seu leitor, fazemos, no entanto, atentar para o frequente recurso aos jogos de palavras também num grande comediógrafo como Plauto:

$$
\begin{aligned}
& \text { Estr. - Que desejas? } \\
& \text { Eu. - Deixa-a (a marmitinha). } \\
& \text { Estr. - Por Pólux, velho, estou certo de que costumas dar } \\
& \text { sempre! }^{42}
\end{aligned}
$$

O picante trocadilho acima, que consta da Aulularia, no momento em que Euclião, o pai avaro de Fedra, cobra de Estróbilo, um escravo esperto responsável pelo roubo de sua marmitinha cheia de ouro, a devolução do pertence, dá-nos um bom exemplo da arte plautina no manejo cômico dos vocábulos. De fato, segundo um procedimento que nos parece intraduzível em português, a resposta de Euclião ao escravo recorrera ao imperativo

\footnotetext{
${ }^{41}$ Além, é claro, da irônica ambiguidade da expressão como um todo, a qual aponta, em si, para um indistinto movimento das mãos nos prazeres ou nos trabalhos físicos.

${ }^{42}$ PLAUTO. Amphitruo. Asinaria. Aulularia, p. 312 (tradução nossa do latim).
} 
do verbo ponere (pone - depõe, deposita, deixa...), e, obviamente, indicava o desejo do velho de que Estróbilo largasse a panelinha que tinha roubado de seu esconderijo no templo da deusa Fides (Boa-Fé). Contudo, segundo maliciosamente interpretada pelo escravo, a expressão assume um sentido obsceno, como observado por Ettore Paratore, tradutor da edição plautina de que nos servimos: pone, neste caso, entendeu-se por um advérbio significando "por detrás", como se os desejos de Euclião em relação a Estróbilo estivessem revestidos de outras intenções. Na sequência do diálogo entre essas duas personagens, o frequentativo datare (dar sempre, dar muitas vezes...), cujo sujeito é um pronome pessoal a remeter a Euclião, confirma, na despistadora resposta do escravo, as conotações sexuais que quisera atribuir à fala do velho, evitando, assim, confessar-se o ladrão do ouro e, ao mesmo tempo, ofendendo-o em sua virilidade.

Por fim, esclarecemos que, além das proposições teóricas de alguns críticos, ${ }^{43}$ o texto mesmo do De re rustica varroniano parece, por vezes, convidar a cotejá-lo com o universo da produção dramática. Referimo-nos, especificamente, aos termos pars e actus (ato e papel), por vezes explicitados na tessitura da obra em contextos metalinguísticos, ou seja, de comentário das personagens sobre a própria interação nos diálogos e sobre o andamento dos mesmos: a propósito de De re rustica II, então, encontramo-los, por um lado, em 5, 2 e 10, 1 e, por outro, em 5, 2/ 8, 1 e 10, 1. Lembramos, aqui, a face poligráfica de Varrão, e que o autor, inclusive, compôs suas perdidas Quaestiones plautinae antes de dedicar-se à escrita do De re rustica como derradeira obra, já quase aos 90 anos. $^{44}$

\footnotetext{
${ }^{43}$ AGACHE. Construction dramatique et humour dans le "Traité d'agriculture" de Varron, p. 219.

${ }^{44}$ Cf. introdução do volume de Harvard para a tradução de Hooper e Ash das obras de Catão e Varrão (CATO; VARRO. On agriculture, p. XVII).
} 
Um ponto pertinente para o exame da terminologia teatral varroniana, tal como incorporada ao De re rustica $\mathrm{II}$, diz respeito a algumas discussões sobre o exato sentido de actus na dramaturgia antiga: assim, se Horácio (v. 189-190), na Epistula ad Pisones ${ }^{45}$ o gramático tardio Donato ${ }^{46} \mathrm{e}$, como vimos, Varrão recorreram sem falta ao termo, nenhuma menção se faz a isso, por exemplo, em todo o corpus das peças de Plauto. ${ }^{47}$ Dada, porém, sua inegável influência na metalinguagem dramática dos críticos romanos e, aliás, mesmo na interna à obra de nosso interesse, algum olhar para o tema se justifica.

Evidentemente, o significado de actus se vincula à questão de sabermos se as Comédias latinas eram ou não divididas, na encenação, por entreatos a pausarem, durante ausências representativas em si sobre o palco, ofluxo do desenvolvimento dramático. Para um estudioso mais antigo, como Freté, esse seria precisamente o caso. Baseando-se em supostos indícios, para ele, depreensíveis do encaminhamento da ação, afirma, sobre uma peça como a Aulularia plautina:

Em 279, o entreato é indispensável. Megadoro partiu em direção à praça, 264, com seu escravo Estróbilo, para comprar mantimentos em vista da dupla refeição de bodas: aquela que se celebrará em sua casa e aquela cujos gastos Euclião não saberia cobrir. No verso 280, vê-se voltar da praça Estróbilo, escoltado por carregadores de mantimentos que acompanham os dois carneiros (327ss), de dois cozinheiros elogiados por Megadoro e de duas tocadoras de flauta $(281,332 s s)$, igualmente elogiadas. Todo o mundo segue sem pressa para a casa, Estróbilo e os dois cozinheiros tagarelam e fazem bagunça;

\footnotetext{
${ }^{45}$ HORÁCIO. Epistula ad Pisones, p. 60.

${ }^{46}$ FRETÉ. La structure dramatique des comédies de Plaute, p. 6.

${ }^{47}$ FRETÉ. La structure dramatique des comédies de Plaute, p. 9.
} 
Estróbilo alude às ordens dadas por Megadoro na praça, depois de ter terminado suas compras, em termos tais que as palavras do dono não parecem de todo recentes (postquam opsonauit erus..., 280-281). Como imaginaria o espectador que tudo isso se passou durante o curto trecho 275-279? Por outro lado, Euclião partiu ele mesmo em direção à praça, 274 , e, se ele tivesse acabado de cruzar com o "cortejo", isso se mostraria nas primeiras palavras que Estróbilo fala a seu respeito (290ss). É de fato necessário que tenha havido um entreato. ${ }^{48}$

O estudioso francês, portanto, postula não só a existência de actus (atos) como grupos independentes de cenas "perfeitamente homogêneas", "em cujo interior cada entrada de uma nova personagem é vista e constatada pelas personagens que se encontram no palco", ${ }^{49}$ mas, ainda, entende que há um número variável deles em cada peça de Plauto. Beare, por sua vez, num ensaio mais atual, opina diversamente, a saber, pela cautela: citando embora as palavras do gramático antigo Donato, que defende a vigência de cinco atos nas peças de Terêncio, e o aludido testemunho da Poética horaciana, na qual se lê essa informação de maneira preceituadora, ${ }^{50}$ o crítico considera as chances de corresponder o mesmo termo antigo a um conceito diferente do moderno. Assim, para Beare, "os romanos queriam dizer por actus uma seção de uma peça representada por atores e circunscrita por algo não representado por atores, como uma canção pelo coro. Nós queremos dizer com 'ato' uma seção de uma peça circunscrita por pausas na performance". ${ }^{51}$

\footnotetext{
${ }^{48}$ FRETÉ. La Structure dramatique des comédies de Plaute, p. 22-23. (tradução nossa do francês; grifo do autor)

${ }^{49}$ FRETÉ. La Structure dramatique des comédies de Plaute, p. 62.

${ }^{50}$ BEARE. Roman origin of five-act law, p. 50.

${ }^{51}$ BEARE. Roman origin of five-act law, p. 49.
} 
O posicionamento de Grimal a respeito do teatro romano, ainda, é claro: segundo ele, numa obra de divulgação relativamente recente, a Comédia latina nunca conheceu, em si, qualquer quebra em atos, sendo representada de modo ininterrupto do início ao fim dos espetáculos. A despeito de ter sido tributário da Nea grega (em que um ato era um segmento de peça entre dois embolima cantos corais), o teatro de Plauto e Terêncio não obedeceu, observa, ${ }^{52}$ à tardia preceituação da Poética, que propugnava, além de pela efetiva existência dos actus segmentados, também por fixar-lhes inflexível o número em cinco para a Tragédia e a Comédia. ${ }^{53}$

Sem ser necessária a resolução de todos os impasses vinculados aos meios de performance dramática antiga, os actus, então, parecem ter sido compreendidos pelo Varrão do De re rustica ao menos como partes de peças teatrais contínuas (sentido não anacrônico, para Beare), ou, metaforicamente, de seus diálogos: ele sempre emprega o termo em pontos nos quais, decorrida uma parcela da exposição técnica, vai-se dar curso a ela em direções distintas. Quanto às partes de que se incumbem personagens como Vácio, trata-se de um termo claramente documentado nos dramaturgos romanos, segundo testemunha este simples par de versos do Amphitruo:

E então? Já que aqui escravo também tem papéis, $\quad 62$ farei com que seja assim como disse, uma tragicomédia. ${ }^{54}$

Em De re rustica II, assim, Varrão imita com bom humor homens coevos a si, atribuindo-lhes, para além de sua voz de narrador, a expressão direta. Por outro lado, certas personagens desse diálogo pecuário têm nomes bastante sugestivos de seus

\footnotetext{
${ }^{52}$ GRIMAL. O teatro antigo, p. 98-99.

${ }^{53}$ Cf. nota 44 deste texto.

${ }^{54}$ PLAUTO. Amphitruo. Asinaria. Aulularia. Bacchides, p. 58. (tradução nossa do latim)
} 
papéis na exposição que se desenrola, doravante, diante de nossos olhos, movimentam-se num plano temático e, talvez, espaçotemporal harmônico e capaz de atribuir a esse livro seu peculiar tom no cotejo com os demais, não são estranhas aos jogos vocabulares e, enfim, também atuam nos "atos" engendrados pela ficção varroniana. Esperando ter demonstrado os motivos de serem esses os pontos de contato entre o segundo livro do De re rustica e a produção cômica antiga, por ora nos damos por satisfeitos se explicitamos algo do nuançamento literário desta curiosa obra técnica antiga.

Résumé: Le deuxième livre du De re rustica de Varron réatin $\left(1^{\text {er }}\right.$ siècle av. J.-C.), comme les autres du même ouvrage, présente aussi, quoiqu'il appartienne au genre dialogique de la littérature ancienne, des ressemblances avec la Comédie greco-latine. Nous nous proposons ici d'en élucider les caractéristiques qui nos permettent cette dernière affirmation.

Mots-clés: Littérature classique; Varron; genre dialogique; Comédie.

\section{REFERÊNCIAS}

AGACHE, S. Construction dramatique et humour dans le "Traité d'agriculture" de Varron. In: TRÉDÉ, M.; HOFFMANN, P. (Org.). Le rire des anciens. Paris: Presses Universitaires de l'École Normale Supérieure, 1998. p. 201-230.

ARISTÓTELES. HORÁCIO. LONGINO. A poética clássica. Trad. Jaime Bruna. São Paulo: Cultrix, 2005.

BEARE, W. Roman origin of five-act law. Hermathena, Dublin, n. LXXII, p. 44-70, 1948.

CATO; VARRO. On agriculture. With an English translation by W. D. Hooper and H. B. Ash. Cambridge, Mass./ London: Harvard University Press, 2006. 
CLAY, D. The origins of the socratic dialogue. In: WAERDT, P. A. V. (Org.). The socratic movement. Ithaca/ London: Cornell University Press, 1994.

FRETÉ, A. La structure dramatique des comédies de Plaute. In: MAROUZEAU, J. (Org.). Collection d'études latines. Paris: Les Belles Lettres, 1930. p. 5-68. v. VI.

GAILLARD, S.; MARTIN, R. Les genres littéraires à Rome. Paris: Nathan/ Scodel, 1990.

GRIMAL, P. La littérature latine. Paris: Fayard, 1994.

GRIMAL, P. O teatro antigo. Trad. António M. G. da Costa. Lisboa: Edições 70, 1986.

GRIPP, B. A língua presa de Fidípides. Nuntius Antiquus, Belo Horizonte, n. 3, p. 69-84, 2009.

LAUGHTON, E. Humour in Varro. In: COLLART, J. (Org.). Varron, grammaire antique et stylistique latine. Paris: Les Belles Lettres, 1978. p. 105-111.

MAROUZEAU, J. Traité de stylistique latine. Paris: Les Belles Lettres, 1946.

MARTIN, R. Recherches sur les agronomes latins et leurs conceptions économiques et sociales. Paris: Les Belles Lettres, 1971.

PLAUTO. Amphitruo. Asinaria. Aulularia. Bacchides. A cura di Ettore Paratore. Roma: Tascabili Economici Newton, 2004.

ROBERT, R. La vie à la campagne dans l'Antiquité romaine. Paris: Les Belles Lettres, 1985.

RUCH, M. Le préambule dans les ouvres philosophiques de Cicéron. Essai sur la genèse et l'art du dialogue. Paris: Les Belles Lettres, 1958.

SHERK, R. K. The eponymous officials of Greek cities. Zeitschrift für Papyrologie und Epigraphic, Bonn, v. XCVI, p. 267-295, 1993.

SUETÔNIO. AUGUSTO. A vida e os feitos do divino Augusto. Trad. Matheus Trevizam, Paulo S. de Vasconcellos e Antônio M. de Rezende. Belo Horizonte: UFMG, 2007.

TERÊNCIO. A sogra. Trad. Walter de Medeiros. Brasília: UNB, 1994. 
TRAGLIA, A. Varrone e la prosa letteraria del suo tempo. In: Studi su Varrone, sulla retorica, storiografia e poesia latina. Rieti: Centro di Studi Varroniani, 1979. p. 497-539.v. II.

TREVIZAM, M. Linguagem e interpretação na literatura agrária latina. Tese Doutorado (Pós-graduação em Linguística do IELUNICAMP, área de Língua e Literatura Latina). Campinas: UNICAMP, 2006.

Recebido para publicação em 31 de janeiro de 2010 Aprovado em 29 de junho de 2010 